\title{
A Microcontroller-based Intelligent System for Real-time Flood Alerting
}

\author{
M. Oprea, V. Buruiana, A. Matei
}

\author{
Mihaela Oprea, Vasile Buruiana, Alexandra Matei \\ University Petroleum-Gas of Ploiesti, Department of Informatics \\ Bdul Bucuresti No 39, 100680, Ploiesti, Romania \\ E-mail: mihaela@upg-ploiesti.ro, bvasea@gmail.com, matei.alexandra@hotmail.com
}

\begin{abstract}
The development of efficient flood alerting systems became more demanding in the last years. In this paper it is presented the first version of a prototype intelligent system for flood forecasting and real-time alerting. The system is implemented by using a microcontroller from the ARM family, Marvell 88F6281, and has a user interface realized under the Free UnixBSD operating system. Also, a knowledge base is integrated in the system. The real-time alert is sent to the decision making factors via a communication channel (such as, the internet, a mobile phone, or radio communication). Some experimental results obtained so far are also discussed in the paper.
\end{abstract}

Keywords: microcontroller, flood, artificial intelligence.

\section{Introduction}

The development of an efficient hydrologic monitoring system requires the use of an automated data acquisition system, the analysis of several parameters that are monitored (water level, water flow, rainfall fell etc), and a real-time alerting system in case of flood production. As hydrologic monitoring is very important in flood prevention, in the last years, different modern techniques were applied for flood forecasting, including some artificial intelligence based approaches, such as expert systems, artificial neural networks, intelligent agents and multiagent systems (see [8]). The systems that were reported in the literature are specific to a given hydrographic basin or to a dam or river, and provide particular solutions, which hardly can be adapted and used in other situations. Our long term research purpose is to design and implement a prototype intelligent system for flood forecasting that provides real time alert in case of flood production, and can be adapted to any hydrographic area (basin, river or dam) with minimal infrastructure changes. The objective is to develop a flexible and robust intelligent system by keeping it as simple as possible. Some related work reported by the research community in the area of real time alert systems provides solutions such as the embedded controller systems (see [2]), the microprocessor systems (see [3]), and the mobile sensor nodes for alert systems applications (see [9]). A preliminary report on the use of the microcontroller-based system, described in this paper, was given in (see [5]), where the application was in the area of real time seismic alert, and no artificial intelligence technique was used. We have started the development of an intelligent prototype system from our previous work described in (see [5]) (data acquisition and alert transmition), (see [6]) (implementing a low power, high performance BSD Unix microcontroller-based system), (see [7]) (intelligent algorithms) and (see [8]) (agent-based modelling).

In this paper it is presented the first version of a prototype intelligent system for flood forecasting and real-time alerting. The system is implemented by using a microcontroller from the ARM-family, and has a user interface realized under the UnixBSD operating system, and a knowledge base integrated in the system. The real-time alert is sent to the decision making factors 
via Internet or mobile phone or by radio communication. The experimental results obtained so far are also discussed in the paper.

\section{The architecture of the microcontroller-based intelligent sys- tem}

The microcontroller-based intelligent system was designed arround the Marvell 88F6281 microcontroller by using the Marvell Sheevaplug development platform (see [11]), and the Unix Free BSD 8.0 Beta 2 operating system (OS) (see [12]) . The architecture of the system is presented in figure 1.

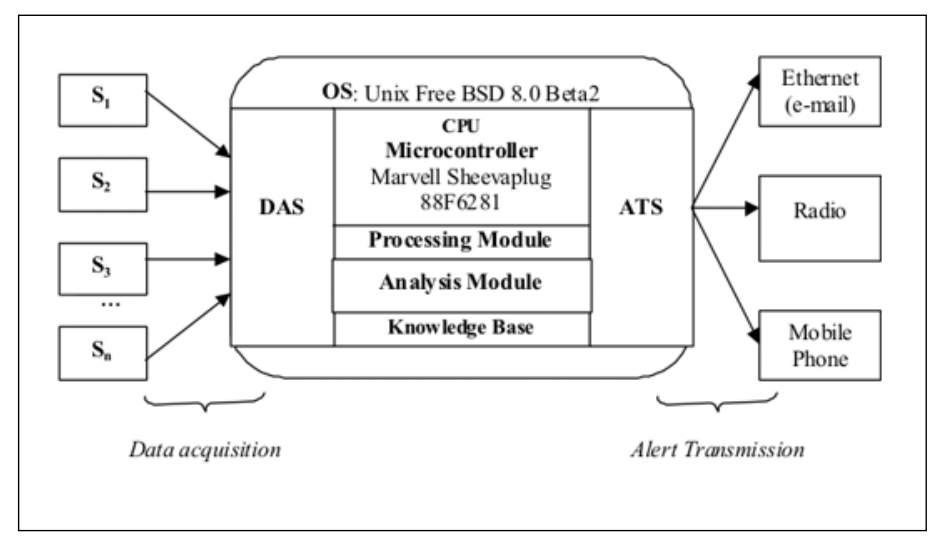

Figure 1: The architecture of the system

As interfaces with the environment, the intelligent system has a data acquisition system (DAS), and an alert transmission system (ATS), both systems being developed within the microcontroller Marvel 88F6281. The data acquisition system takes the measurements of different parameters that are monitored from a variety of sensors $\left(S_{i}\right)$ and measurement devices (e.g. rain gauges). The alert transmission system will send the hydrologic alert code through a communication channel (internet, radio or mobile phone) to the decision factors. We have included also in the microcontroller a data processing module, a knowledge base, and an analysis module, those based on the knowledge of the intelligent system will provide the hydrologic alert code to ATS.

The microcontroller 88F6281 is built under the SoC form, i.e. system on chip, and has a large variety of interfaces as shown in figure 2. Its main destination is the mobile telephone market due to its multimedia facilities.

We have compiled on this system the Unix FreeBSD 8.0 operating system, available in the beta version, due to its stability and simple programming (see [4]). This OS provides support for the ARM9 architecture, and it was compiled with the specifications of the 88F6281 microcontroller according to (see [6]). Moreover, the OS that was chosen is a good option for embedded real time applications (see [1]).

The hydrologic alert transmission could be sent by email, SMS (on the mobile phone) or by radio transmission (e.g. to a PDA - Personal Digital Assistant).

\section{$3 \quad$ Hydrographic monitoring and analysis system}

The monitoring and analysis system of a catchment basin structure consists by a complex of sensors that acquire information about the monitored river parameters, as well as rainfalls in the catchment area. Another important set of information is given by the catchment physiographic 


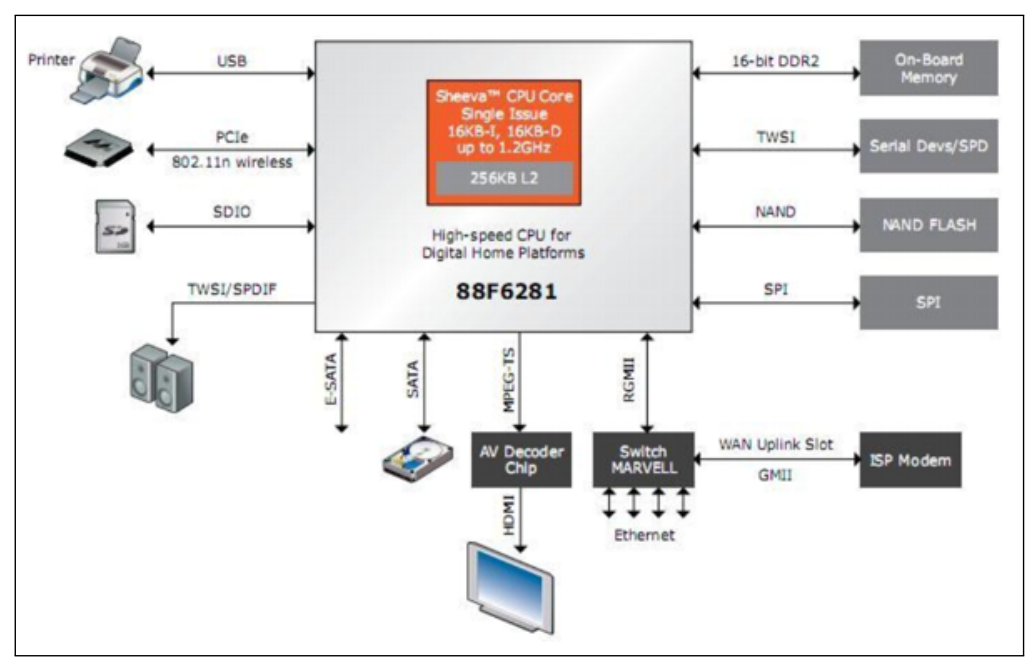

Figure 2: The Marvell Sheeva 88F6281 interfacing options

characteristics that influence the flow regime during the flood (see [10]). Our hydrographic monitoring and analysis system was designed for the monitoring of the evolution process of rainfall transformations into collecting streams by the hydrographic network from one river basin. The system is able to acquire and store the database information on river water level $(\mathrm{H})$, current river speed $(\mathrm{v})$, water flow rates $(\mathrm{Q})$, the rainfalls level and frequency $(\mathrm{X})$ etc and transmit them to higher level of the analysis tasks. After the information processing is done by using the analysis algorithms (see [7]), the system has the ability to make decisions and to transmit alerts to the Committee of Emergency Situations in case of flood risks.

The input data used by the system can be obtained from parameters measurements timeseries. The analyzed parameters are as follows:

- the river water level $(\mathrm{H}-\mathrm{cm})$, measured by the gauging stations that are located in different regions of the catchment;

- the rainfalls quantity $\left(\mathrm{X}-\mathrm{l} / \mathrm{m}^{2}\right)$;

- the river water velocity $(\mathrm{v}-\mathrm{m} / \mathrm{s})$;

- the air temperature $\left(\mathrm{T}-{ }^{\circ} \mathrm{C}\right)$;

- the depth (a), width (L) and slope (p) of the river;

- the thickness of the ice/snow $(\mathrm{G}-\mathrm{cm})$.

The output of the system is given by the numerical expressions that characterize the interdependence of the hydrological process and the factors that determine it: the maximum flow rate $\left(\mathrm{Q}_{\max }\right)$ and the average precipitation. The main steps followed by the hydrographic monitoring and analysis system are given bellow.

1. parameters_measurement $(\mathrm{H}, \mathrm{Q}, \mathrm{X}, \mathrm{v}, \mathrm{T}, \mathrm{a}, \mathrm{l}, \mathrm{p}, \mathrm{G})$;

2. parameters_processing $(\mathrm{H}, \mathrm{X})$;

3. parameters_transmission $\left(\mathrm{X}_{\text {average }}\right)$;

4. parameters_analysis (); // use of the knowledge base 
5. IF flood_risk $=$ yes THEN

(a) hydrologic alert code transmission.

The parameters measurement step requires periodic measurements of specific parameters such as water flow, water level, river flow rate, temperatures. The equipment used for performance measurements and processing of hydrological parameters of the water courses are the gauging stations. The instrumentation used for parameters measuring vary from groom gauging, pluviometric devices to measure the rainfall, river ratchets gauging for speed measurements, to automatic instrumentation that can measure most of the hydrological parameters that are monitored. The parameters processing step involves the form factor computing for each sub-catchment coefficient of flood form, and the determination of the coefficient of leakage in the warning subbasins. The parameters transmission step is realized through a communication channel, such as internet, radio or mobile phone. The parameters analysis step is the most important step because the subsequent correct decisions are taken in case of flood waves. It consists in the following three steps:

- determination of the average level of precipitations;

- calculation of the maximum flow in each sub-basin of the downstream warning sub-basins;

- based on the calculations made in the previous two steps, the system analyses the risk of flood production by using the rules from the knowledge base that is incorporated in the intelligent system; the rules are given the hydrological alert code (yellow, orange and red).

As an example, the main characteristics of the knowledge based system are presented in Table 1.

Table 1: The rules of the knowledge base (selection)

\begin{tabular}{|l|l|}
\hline RULE 1 & IF flow $<$ attention AND precipitations $<40 \mathrm{l} / \mathrm{m}^{2}$ THEN hydrologic_code $=$ green; \\
\hline RULE 2 & $\begin{array}{l}\text { IF flow } \geq \text { attention AND flow }<\text { alert AND precipitations }<40 \mathrm{l} / \mathrm{m}^{2} \text { THEN } \\
\text { flood_risk }=\text { YES AND hydrologic_code }=\text { yellow; }\end{array}$ \\
\hline RULE 3 & $\begin{array}{l}\text { IF flow } \geq \text { attention AND flow }<\text { alert AND precipitations }>40 \mathrm{l} / \mathrm{m}^{2} \text { THEN } \\
\text { flood_risk }=\text { YES AND hydrologic_code }=\text { orange; }\end{array}$ \\
\hline RULE 4 & $\begin{array}{l}\text { IF flow } \geq \text { alert AND flow }<\text { danger AND precipitations }<40 \mathrm{l} / \mathrm{m}^{2} \text { THEN flood_risk } \\
=\text { YES AND hydrologic_code }=\text { orange; }\end{array}$ \\
\hline RULE 5 & $\begin{array}{l}\text { IF flow } \geq \text { alert AND flow }<\text { danger AND precipitations }>40 \mathrm{l} / \mathrm{m}^{2} \text { THEN flood_risk } \\
=\text { YES AND hydrologic_code }=\text { red; }\end{array}$ \\
\hline RULE 6 & IF flow $\geq$ danger THEN flood_risk = YES AND hydrologic_code $=$ red; \\
\hline
\end{tabular}

The precipitations are occurring predominantly as rain or snow. The fall of rain is the largest factor contributing to increased river flows. Snow versus rain is the second source of precipitation. Melting snow during spring has a considerable impact on river basin management. Tracking the level and the periodicity of precipitation involves measuring them by using existing sensors and transducers gauging stations. Warning about the risk of flood is used to take appropriate decisions from the analysis of all information related to the maximum river flow. If the analysis step indicates a possible flood production then the prevention system will send signals to the members of the Emergency Situations Committee. The hydrological alert (containing the alarm severity code of flooding) can be transmitted online to PDAs, smart terminals with a GPS and 


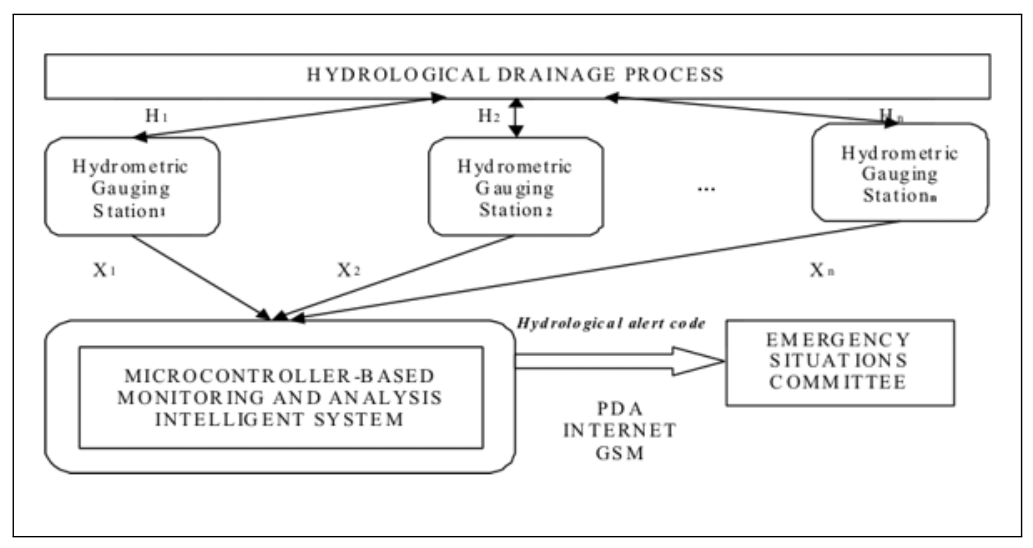

Figure 3: The structure of the monitoring and analysis system

GPRS (General Packet Radio Service) or Internet. In figure 3 it is shown the structure of the monitoring and analysis system for a catchment river basin.

$X_{1}, X_{2}, \ldots, X_{n}$ are the rainfalls in each sub-catchment;

$\mathrm{H}_{1}, \mathrm{H}_{2}, \ldots, \mathrm{H}_{\mathrm{n}}$ are the rivers level.

The system meets three important functions:

- the function of monitoring the evolution of the hydrographic basin - real time measuring of the river level and rainfall level and periodicity;

- the analysis function - parameters processing and comparing them with the references parameters of the catchment;

- the decision and warning function.

\section{Experimental results of flood alerting case study}

As a case study we have experimented the microcontroller-based intelligent system for flood alerting in the Prahova catchment basin presented in figure 4. The hydrographic network forms a highly developed basin in a palm form flowing NW-SE. The main rivers that compose the Prahova sub-basin are the Prahova river and its main tributaries: Azuga, Doftana, Teleajen, and Cricovul Sarat. The water recources in the Prahova country have increased significantly due to two large lakes, Paltinu (Doftanei Valley) and Maneciu-Streams (Teleajen Valley). The Prahova river is the largest collection of water in the Prahova county, with a length of $193 \mathrm{~km}$, of which the first $6 \mathrm{~km}$ and the last $16 \mathrm{~km}$ are located in the counties Brasov and Ilfov.

The Prahova river basin is characterized by three types of climates: mountain, hill, and plain. The annual quantity of precipitation is $1000-1400 \mathrm{~mm}$ in the mountains, $500-1000 \mathrm{~mm}$ in the hills, and 550-600 $\mathrm{mm}$ in the plain. Summer rainfall is more abundant, where the flood may occur in the gauging stations deepened Moara Domneasca and Adancata. For the visualization of the hydrological process evolution in time we have used the program Multi Router Trafic Grapher (mrtg) that generates graphics as a function of time. An example of Prahova river level evolution and flow in 24 hours during 7 days is given in figure 5 .

For the Prahova hydrometric station the attention (ATC), alert (AC) and danger (DC) cotes for the rivers level are the following: $\mathrm{ATC}=250 \mathrm{~cm}, \mathrm{AC}=350 \mathrm{~cm}$ and $\mathrm{DC}=400 \mathrm{~cm}$ and for water flow are: $A T C=105 \mathrm{~m}^{3} / \mathrm{s}, \mathrm{AC}=230 \mathrm{~m}^{3} / \mathrm{s}$ and $\mathrm{DC}=320 \mathrm{~m}^{3} / \mathrm{s}$. Our research goal was to use the microcontroller-based intelligent system, that was presented in the previous sections, 


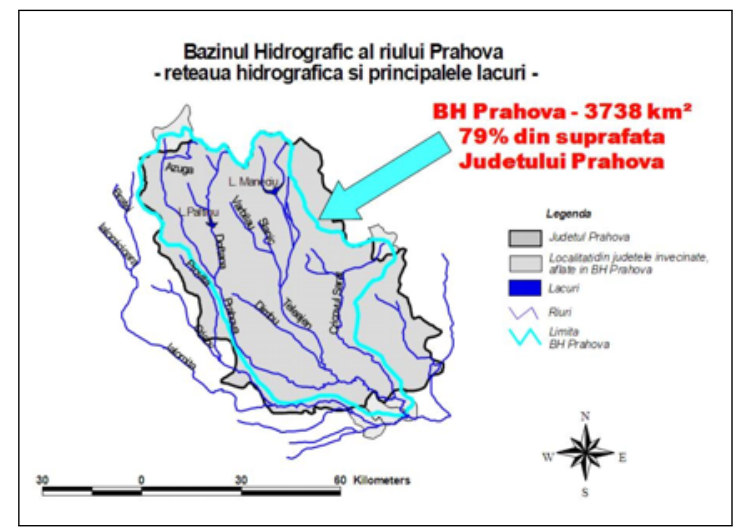

Figure 4: The Prahova catchment basin

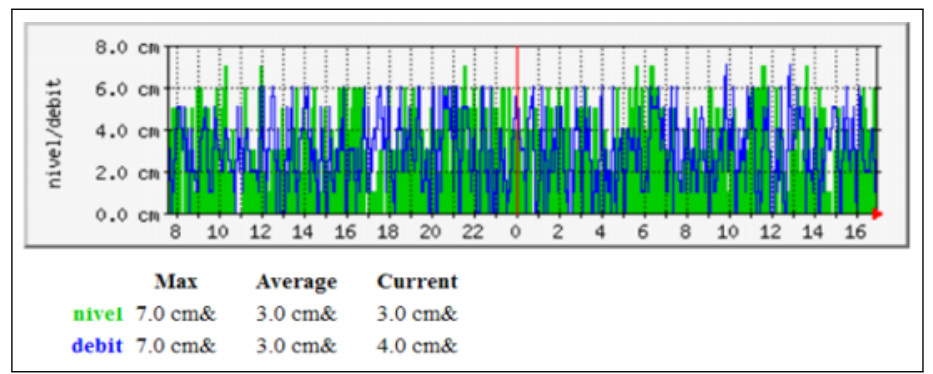

Figure 5: The evolution of Prahova river level and flow in 24 hours during 7 days

for the Prahova river basin with the purpose of sending warning in real time to the Emergency Situations Committee, and to the possible affected population in case of flood waves.

In the experiments that were run so far, the data acquisition was simulated. The experiments made so far used for alert transmission two Motorola MX300 radio transmission stations, those were modified to work in the $146 \mathrm{MHz}$ bandwidth. Figure 6 shows the Motorola MX300 radio stations that were used.

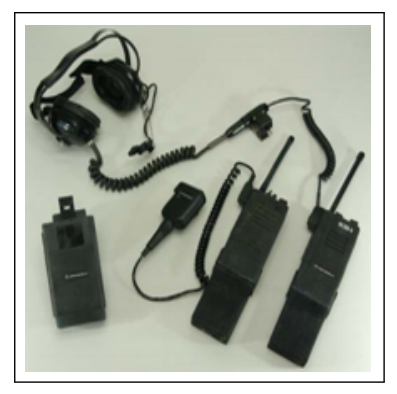

Figure 6: The two Motorola MX300 radio stations

The main characteristics of the radio stations are that they can be automatically activated when they receive a radio signal through the incorporated microphone or through the microphone input. Therefore, the sound output of the microcontroller-based system was connected to the microphone input of the transmitter and according to the hydrologic alert code provided by the analysis module will run audio alert records according to following script:

The evolution of the simulated hydrological process is shown on the microcontroller-based 


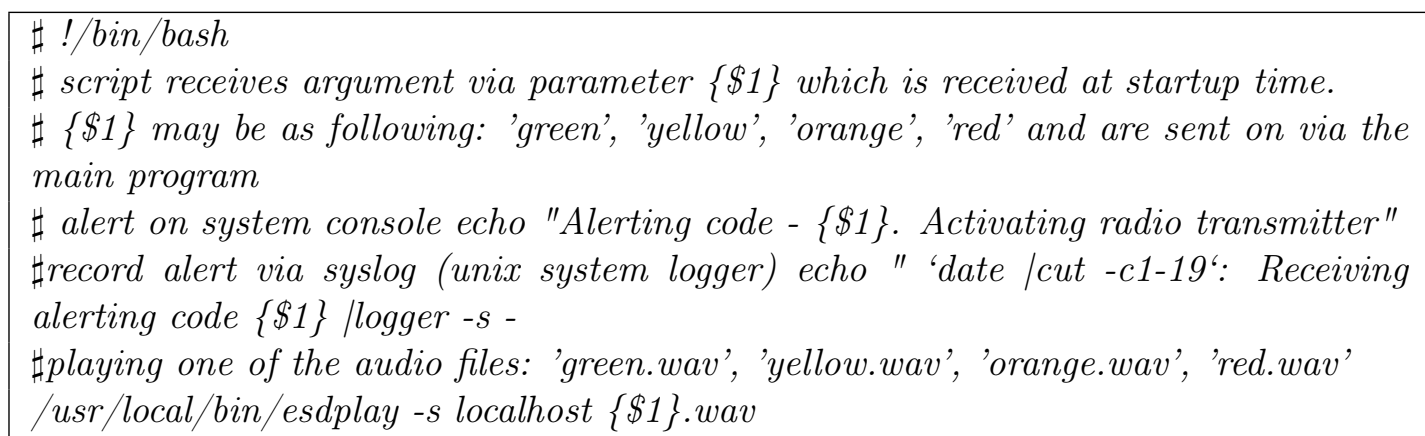

intelligent system screen as shown in figure 7. Three hydrometric gauging stations were included in the simulation, Buşteni, Cîmpina and Prahova, all for the Prahova river basin.

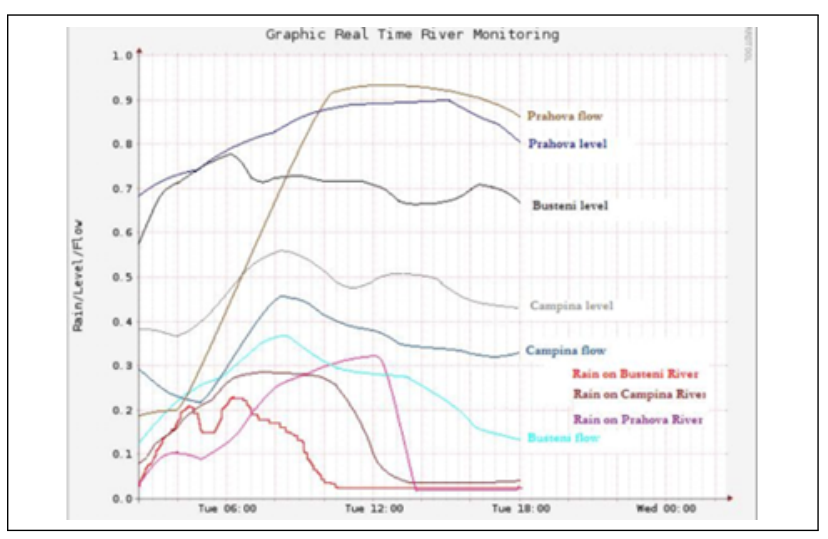

Figure 7: Rain/Level/Flow evolution for the case study

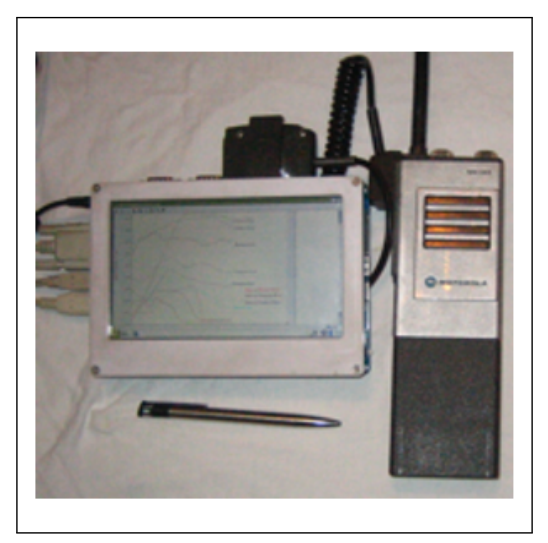

Figure 8: The experimental system

Figure 8 shows the experimental system. In the experiments made, for each hydrological alert code it was sent via radio communication the corresponding audio alert signal (attention, alert and danger), according to the results of the analysis step.

\section{Conclusions}

As most of the hydrological processes require real time monitoring and online alerting, we have developed a microcontroller-based intelligent system that can be connected to various sensors and measuring devices for hydrological parameters measurements, and can transmit online hydrological alert codes to the decision making factor (such as Emergency Situations Committee that exist in each county from Romania). The system can be adapted to any hydrographic basin with minimal changes in its configuration. At the time the system was developed, all the data coming in was simulated, but at any time its knowledge base system can be fed with data coming from real sensors. During long time hard condition tests under simulated air humidity, simulated power fluctuations, while running a CPU stress testing program and also our simulation software, the intelligent system kept its main characteristics of flexibility and robustness, as no indicators of system failure have occurred at Unix FreeBSD 8.0 operating system kernel level. As a future work we shall extend our experiments by using simultaneously with the radio hydrological alert transmission other communication channels such as the internet (by sending an e-mail) and the 
mobile phone (by sending a SMS). Also, we shall analyze some complex hydrological situations by taking into account the interdependencies between different rivers flows and levels from a hydrographic basin and the meteorological forecasts, improving flood prevention due to an early hydrological alert sent to the decision making factors in order to take more efficient prevention measurements.

\section{Bibliography}

[1] D. Abbot, Linux for embedded real-time applications, Newnes, USA, 2003.

[2] K. Arnold, Embedded controller hardware design, LLH Technology Publishing, USA, 2001.

[3] S. R. Ball, Embedded microprocessor systems - real world design, 3rd edition, Newnes, USA, 2002.

[4] BSDi, The FreeBSD Handbook, Berkeley University of California, USA, 2000.

[5] V. Buruiana, Wireless Seismic Sensor, Proceedings of Process Control Symposium SPC-09, Ploiesti, 2009.

[6] V. Buruiana, Experimental Research regarding the Development of a Microcontroller-Based Intelligent Monitoring and Alert System, Research Report, University Petroleum-Gas of Ploiesti, Department of Informatics, 2009.

[7] A. Matei, Intelligent Algorithms for Hydrographic Monitoring, Analysis and Prediction, Research Report, University Petroleum-Gas of Ploiesti, Department of Informatics, 2009.

[8] M. Oprea, A. Matei, E. Petre, Agent-based Modeling of a Dam Monitoring System, Proceedings of 17th International Conference on Control Systems and Computer Science - CSCS 2009, Politehnica Press, 509-514, 2009.

[9] D. Popescu, R. Varbanescu, A. Iordan, S. Arghir, Interconnection of mobile sensor nodes for alert system applications, Proceedings of CSCS 2009, Politehnica Press, Bucharest, 249-254, 2009 .

[10] I. Watson, A. D. Burnett, Hydrology - An Environmental Approach, Taylor \& Francis, CRC Press, 1995.

[11] http://www.tgdaily.com/hardware-opinion/41525-marvells-plug-computer-a-tiny-discretefully-functional-5-watt-linux-server

[12] ftp://ftp.freebsd.org/pub/FreeBSD/ISO-IMAGES-i386/8.0/8.0-RC2-i386-disc1.iso 